\title{
GAMBARAN PERILAKU HIDUP BERSIH DAN SEHAT (PHBS) DI WILAYAH KERJA PUSKESMAS BULU KABUPATEN SUKOHARJO BULAN JANUARI-MARET 2015
}

\author{
Ayu Khoirotul Umaroh'), Heru Yuda Hanggara ${ }^{2)}$, Choiri ${ }^{3)}$ \\ Mahasiswa Program Studi Kesehatan Masyarakat \\ Fakultas Ilmu Kesehatan \\ Universitas Muhammadiyah Surakarta
}

\begin{abstract}
Backgroud: Someone's clean and healthy living behaviors (PHBS) is pertaining with the improvement of individual, family, community, and environment health. Based on Ministry of Health data in 2013, households that were active to practice PHBS in Indonesia reached 55, $6 \%$ and 75,1\% in Central Java. Data from District Health Profile of Sukoharjo in 2013, from 114.140 households that were examined, 96.922 (82,2\%) households have applied PHBS The number in Bulu Subdistrict was 85,8\%. However, there are still several villages in the Bulu Subdistrict which had health problems relating to PHBS. Aim: The objective of this research was to describe the clean and healthy living behaviors in Puskesmas Bulu (Gentan village, Kedungsono village, and Kamal village). Method: this reseach used descriptivequantitative design by using Total Sampling tehnique, processing data used a statistic software and data analysing by univariate. Results: PHBS'scope of Gentan village was 67,06\%, Kedungsono village was 73,3\% and Kamal village was 73,53\%. There were four PHBS indicators that showed low percentages, such as the availability of trash bin (37,58\%), health insurance $(49,43 \%)$, no smoking $(52,81 \%)$ and usage of mosquito nets $(56,65 \%)$. The highest percentage of PHBS indicators were no drinking and drugs $(96,28 \%)$ and the availability of clean water $(94,88 \%)$. Conclusion: the percentage of PHBS'scope in those three villages were lower than national percentage target (80\%) in 2014-2019. Suggestion: health staff should activate the health cadres in these villages, to give comprehensive health education to the community and evaluate their PHBS continously.
\end{abstract}

Keywords: PHBS, national target, the rate scope

\begin{abstract}
Abstrak. Latar belakang: Perilaku hidup bersih dan sehat seseorang sangat berkaitan dengan peningkatkan kesehatan individu, keluarga, masyarakat dan lingkungannya. Data Kementrian Kesehatan tahun 2013, bahwa rumah tangga di Indonesia yang mempraktekkan PHBS baru mencapai 55,6\%, di Jawa Tengah sebesar 75,1\%. Data Profil Kesehatan Kabupaten Sukoharjo tahun 2013, dari 114.140 rumah tangga yang diperiksa PHBS, sebanyak $96.922(82,2 \%)$ rumah tangga yang sudah menerapkan perilaku hidup bersih dan sehat dan kecamatan Bulu pada tahun 2013 sebesar 85,8\%. Namun masih terdapat beberapa desa di kecamatan Bulu yang memiliki permasalahan kesehatan berkaitan dengan PHBS. Tujuan: mengetahui gambaran perilaku hidup bersih dan sehat di wilayah kerja Puskesmas Bulu (Desa Gentan, Desa Kedungsono, Desa Kamal). Metode: jenis penelitian deskriptif kuantitatif menggunakan teknik Total Sampling dan analisis data univariat dengan
\end{abstract}


bantuan software statistik. Hasil: Pencapaian hasil yang didapatkan desa Gentan (67,06\%), desa Kedungsono (73,3\%) dan desa Kamal (73,53\%). Dari ketiga desa tersebut, terdapat empat indikator PHBS yang nilainya terendah, yakni ketersediaan tempat sampah $(37,58 \%)$, kepemilikan JPK $(49,43 \%)$, tidak merokok $(52,81 \%)$, dan PSN (56,65\%). Indikator PHBS dengan nilai tertinggi adalah tidak miras/narkoba $(96,28 \%)$ dan ketersediaan air bersih (94,88\%). Kesimpulan: pencapaian hasil PHBS di desa Gentan, Kedungsono, dan Kamal masih di bawah target nasional di tahun 2014-2019.

Saran: mengaktifkan kader kesehatan di tiga desa tersebut oleh tenaga kesehatan terkait dan memberikan pendidikan kesehatan yang berkelanjutan dan komprehensif kepada masyarakat serta melakukan pendampingan terhadap perkembangan PHBSnya.

Kata kunci: PHBS, target nasional, angka capaian

\section{PENDAHULUAN}

Gerakan Perilaku Hidup Bersih dan Sehat (PHBS) merupakan ujung tombak untuk pembangunan kesehatan dalam rangka meningkatkan perilaku hidup sehat masyarakat. Program PHBS di Rumah Tangga merupakan upaya untuk memberdayakan anggota rumah tangga agar tahu, mau dan mampu mempraktikkan perilaku hidup bersih dan sehat serta berperan aktif dalam gerakan kesehatan di masyarakat. PHBS di Rumah Tangga dilakukan untuk mencapai Rumah Tangga berperilaku hidup bersih dan sehat. Perilaku hidup bersih dan sehat seseorang sangat berkaitan dengan peningkatkan kesehatan individu, keluarga, masyarakat dan lingkungannya. Menurut teori HL BLUM diketahui bahwa status kesehatan individu erat kaitanya dengan perilakunya, semakin baik perilaku yang berhubungan dengan kesehatan maka maka status kesehatanya akan semakin baik.

Rumah Tangga Ber-PHBS didapatkan dari rumah tangga yang seluruh anggotanya berperilaku hidup bersih dan sehat. Indikator ini merupakan indikator komposit dari 16 indikator, yaitu pertolongan persalinan oleh tenaga kesehatan, kunjungan $\mathrm{K} 4$, bayi diberi ASI eksklusif, balita ditimbang setiap bulan, gizi seimbang, menggunakan air bersih, mencuci tangan dengan air bersih dan sabun, menggunakan jamban sehat, memberantas jentik di rumah sekali seminggu, melakukan aktivitas fisik atau berolahraga setiap hari, tempat pembuangan sampah, gosok gigi, lantai rumah, tidak mengkonsusmsi miras dan narkoba, memiliki jaminan kesehatan nasional dan tidak merokok di dalam rumah. Apabila dalam Rumah Tangga tersebut tidak ada ibu yangmelahirkan, tidak ada bayi dan tidak ada balita, maka pengertian Rumah Tangga berPHBS adalah rumah tangga yang memenuhi 12 indikator PHBS.

Program pembinaan PHBS yang dicanangkan pemerintah sudah berjalan cukup lama, namun pada kenyataanya capaian keberhasilannya masih jauh dari harapan. Berdasarkan data Kementrian Kesehatan tahun 2013, bahwa rumah tangga di Indonesia yang mempraktekkan PHBS baru mencapai $55,6 \%$ sedangkan capaian ini masih jauh bila dibandingkan dengan target tahun 2013 yaitu sebesar 65\%. Angka tersebut masih terlampau jauh dengan target Rencana Strategis (Restra) Kementerian Kesehatan tahun 2010-2014 mencantumkan target $70 \%$ rumah tangga sudah mempraktekkan PHBS (Perilaku Hidup Bersih dan Sehat) pada tahun 2014.

Berdasarkan data Kementrian Kesehatan Indonesia (Kemenkes) tahun 2013, cakupan rumah tangga berperilaku hidup bersih dan sehat di Jawa Tengah sebesar 75,1\%, capaian ini sudah memenuhi target bila dibandingkan dengan Renstra nasional tahun 2010-2014 yaitu sebesar $70 \%$. Berdasarkan data Profil 
Kesehatan Kabupaten Sukoharjo tahun 2013, dari 114.140 rumah tangga yang diperiksa PHBS, sebanyak 96.922 rumah tangga yang sudah menerapkan perilaku hidup bersih dan sehat, itu artinya sebanyak $82,2 \%$ masyarakat sudah menerapkan perilaku hidup bersih dan sehat.

Cakupan rumah tangga yang berperilaku hidup bersih dan sehat di kecamatan Bulu pada tahun 2013 sebesar 85,8\%. Angka ini berada di atas cakupan Kabupaten Sukoharjo $(82,2 \%)$. Hal ini menunjukkan bahwa masyarakat yang berada di kecamatan Bulu telah berperilaku hidup bersih dan sehat dengan baik. Namun, masih terdapat beberapa desa yang memiliki permasalahan PHBS yang harus segera diselesaikan. Seperti halnya desa Gentan, Kamal dan Kedungsono yang masih menduduki peringkat ke 8,10 , dan 11 dalam indikator JPK dan peringkat 1, 2 dan 8 dalam prevalensi TB/100.000 penduduk.

\section{METODE PENELITIAN}

Penelitian ini merupakan jenis penelitian deskriptif kuantitatif. Penelitian ini dilaksanakan pada tiga desa di kecamatan Bulu Sukoharjo pada bulan Januari-Maret 2015. Tiga desa tersebut terdiri dari Desa Getan (Dusun Gentan, Dusun Budeh dan Dusun Baseng), Desa Kedungsono (Dusun Kedungsono, Dusun Tiyoko, Dusun Malangan, dan Dusun Suko), dan Desa Kamal (Dusun Lemahbang, Dusun Karangasem, Dusun Ngesong).

Populasi penelitian adalah semua Kepala Keluarga (KK) yang berada di tiga desa penelitian sebanyak 2.466 namun yang aktif hanya 1.254 KK. Pengambilan sampel dengan menggunakan Total Sampling yaitu teknik pengambilan sampel dimana jumlah sampel sama dengan populasi (Sugiyono, 2007). Besar sampel disetiap desa di dapatkan sebanyak Desa Gentan (382 KK), Desa Kedungsono (428 KK) dan Desa Kamal (444 KK).

Pengumpulan data dilakukan dengan instrumen penelitian berupa kuesioner yang terdiri dari pertanyaan 12 indikator PHBS. Pada jenis pengukuran tersebut, peneliti menggumpulkan data secara formal kepada subjek untuk menjawab secara tertulis terhadap pertanyaan yang diberikan yang diberikan oleh peneliti (Arikunto, 2006).

Penelitian ini menggunakan analisis univariat dengan bantuan software untuk menghidung distribusi 12 indikator PHBS di setiap Desa Gentan, Desa Dedungsono, dan Desa Kamal.

\section{HASIL DAN PEMBAHASAN}

\section{Hasil}

Penelitian tentang PHBS yang dilakukan pada tiga desa di kecamatan Bulu yakni desa Gentan, desa Kedungsono dan desa Kamal menggunakan 12 indikator PHBS (gizi seimbang, air bersih, jamban sehat, tempat sampah, lantai rumah, aktivitas fisik, tidak merokok, cuci tangan, gosok gigi, miras/ narkoba, JPK, PSN).

Berdasarkan Tabel 1, dari tiga desa tersebut dengan sampel sebesar $1.254 \mathrm{KK}$ terlihat bahwa indikator yang memiliki pencapaian tertinggi yakni indikator tidak minum minuman keras dan tidak narkoba dengan rata-rata sebesar 96,28\% (Desa Gentan 94,24\%, Desa Kamal 95,5\%, Desa Kedungsono 99,1\%) sedangkan pencapaian terendah yakni indikator ketersediaan tempat sampah dengan rata-rata sebesar 37,58\% (Desa Gentan 26,96\%, Desa Kamal 31,1\%, Desa Kedungsono 54,7\%).

Pencapaian hasil yang didapatkan yakni desa Gentan (67,06\%), desa Kedungsono $(73,3 \%)$ dan desa Kamal (73,53\%). Bila dibandingkan dengan target PHBS dari Renstra Kesehatan RI tahun 2014-2019 sebesar $80 \%$, angka yang didapatkan oleh ketiga desa tersebut masih dibawah target.

Berdasarkan Tabel 1, dari tiga desa tersebut dengan sampel sebesar $1.254 \mathrm{KK}$ terlihat bahwa indikator yang memiliki pencapaian tertinggi yakni indikator tidak minum minuman keras dan tidak narkoba dengan rata-rata sebesar 96,28\% (Desa Gentan 94,24\%, Desa Kamal 95,5\%, Desa Kedungsono 99,1\%) sedangkan pencapaian 
terendah yakni indikator ketersediaan tempat (Desa Gentan 26,96\%, Desa Kamal 31,1\%, sampah dengan rata-rata sebesar 37,58\% Desa Kedungsono 54,7\%).

Tabel 1. Pencapaian PHBS dengan 12 Indikator di Wilayah Kerja Puskesmas Bulu Kabupaten Sukoharjo tahun 2015 (n=1.254 KK)

\begin{tabular}{clcccc}
\hline \multirow{2}{*}{ NO } & \multirow{2}{*}{ Indikator } & \multicolumn{3}{c}{ Cakupan Desa (\%) } \\
\cline { 3 - 5 } & & Gentan & Kamal & Kedungsono & Total \\
\hline 1 & Gizi Seimbang & 73,04 & 75 & 84,8 & 77,61 \\
2 & Air Bersih & 95,55 & 92,6 & 96,5 & 94,88 \\
3 & Jamban Sehat & 78,53 & 92,8 & 90,6 & 87,31 \\
4 & Tempat Sampah & 26,96 & 31,1 & 54,7 & 37,58 \\
5 & Lantai Rumah & 80,63 & 74,1 & 69,2 & 74,64 \\
6 & Aktivitas Fisik & 47,64 & 63,9 & 78,3 & 63,28 \\
7 & Tidak Merokok & 51,04 & 58,1 & 49,3 & 52,81 \\
8 & Cuci Tangan & 83,77 & 91 & 79,2 & 84,65 \\
9 & Gosok Gigi & 70,94 & 91,2 & 79 & 80,38 \\
10 & Tidak Miras/Narkoba & 94,24 & 95,5 & 99,1 & 96,28 \\
11 & JPK & 44,5 & 59,2 & 44,6 & 49,43 \\
12 & PSN & 57,85 & 57,9 & 54,2 & 56,65 \\
Total & & $\mathbf{6 7 , 0 6}$ & $\mathbf{7 3 , 5 3}$ & $\mathbf{7 3 , 2 9}$ & $\mathbf{7 1 , 2 9}$ \\
\hline
\end{tabular}

Sumber: Data Primer

Berdasarkan Tabel 1, dari tiga desa tersebut dengan sampel sebesar $1.254 \mathrm{KK}$ terlihat bahwa indikator yang memiliki pencapaian tertinggi yakni indikator tidak minum minuman keras dan tidak narkoba dengan rata-rata sebesar 96,28\% (Desa Gentan 94,24\%, Desa Kamal 95,5\%, Desa Kedungsono 99,1\%) sedangkan pencapaian terendah yakni indikator ketersediaan tempat sampah dengan rata-rata sebesar 37,58\% (Desa Gentan 26,96\%, Desa Kamal 31,1\%, Desa Kedungsono 54,7\%).

Pencapaian hasil yang didapatkan yakni desa Gentan $(67,06 \%)$, desa Kedungsono $(73,3 \%)$ dan desa Kamal (73,53\%). Bila dibandingkan dengan target PHBS dari Renstra Kesehatan RI tahun 2014-2019 sebesar $80 \%$, angka yang didapatkan oleh ketiga desa tersebut masih dibawah target.

Terdapat 5 indikator dengan pencapaian di atas target nasional yakni ketersediaan air bersih 94,88\% (Desa Gentan 95,55\%, Desa Kamal 92,6\%, Desa Kedungsono 96,5\%), ketersediaan jamban sehat 87,31\% (Desa
Gentan 78,53\%, Desa Kamal 92,8\%, Desa Kedungsono 90,6\%), cuci tangan 84,65\% (Desa Gentan 83,77\%, Desa Kamal 91\%), gosok gigi 80,38\% (Desa Kamal 91,2\%), dan tidak minum-minuman keras serta tidak narkoba 96,28\% (Desa Gentan 94,24\%, Desa Kamal 95,5\%, Desa Kedungsono 99,1\%).

Tujuh indikator lainnya memiliki pencapaian di bawah target nasional yakni gizi seimbang 77,61\% (Desa Gentan 73,04\%, Desa Kamal 75\%), ketersediaan tempat sampah 37,58\% (Desa Gentan 26,96\%, Desa Kamal 31,1\%, Desa Kedungsono 54,7\%), lantai rumah 74,64\% (Desa Kamal 74,1\%, Desa Kedungsono 69,2\%), aktivitas fisik 63,28\% (Desa Gentan 47,64\%, Desa Kamal $63,9 \%$, Desa Kedungsono 78,3\%), tidak merokok 52,81\% (Desa Gentan 51,04\%, Desa Kamal 58,1\%, Desa Kedungsono 49,3\%), JPK 49,43\% (Desa Gentan 44,5\%, Desa Kamal $59,2 \%$, Desa Kedungsono 44,6\%), dan PSN $56,65 \%$ (Desa Gentan 57,85\%, Desa Kamal 57,9\%, Desa Kedungsono 54,2\%).

Selain itu juga terdapat beberapa indikator 
yang angka rata-ratanya melebihi target nasional namun pencapaian di desa kurang dari target nasional. Indikator tersebut adalah cuci tangan (79,2\%) dan gosok gigi (79\%) di desa Kedungsono, ketersediaan jamban sehat $(78,53 \%)$ di desa Gentan.

\section{Pembahasan}

Dari data statistik yang telah didapatkan, angka PHBS ketiga desa tersebut masih di bawah target nasional. Bila dibandingkan dengan capaian rumah tangga yang berperilaku hidup bersih dan sehat di kecamatan Bulu pada tahun 2013 sebesar 85,8\%, angka ketiga desa tersebut juga masih rendah.

Terdapat empat indikator PHBS yang nilainya terendah, yakni ketersediaan tempat sampah, kepemilikan JPK, tidak merokok, dan PSN. Beberapa alasan yang mendasari masih sangat rendahnya ketersediaan tempat sampah di masing-masing desa adalah lahan kosong masih luas, kebanyakan masih menggunakan bungkus makanan berbahan organik sehingga mudah terurai di alam, sistem pembakaran dan membuangnya ke sungai masih menjadi solusi untuk mengurangi gundukan sampah. Berdasarkan penelitian Ashidiqy (2009), tingkat pengetuan responden mempengaruhi perilaku mereka membuang sampah di sungai. Untuk meningkatkan pengetahuan cara pembuangan dan pengolahan sampah rumah tangga diperlukan pendidikan kesehatan dan penyuluhan. Syaifuddin Azwar (2005) mengatakan bahwa semakin banyak ragam sumber informasi atau penyuluhan yang diperoleh seseorang maka semakin baik pengetahuan orang tersebut.

Jaminan Pemeliharaan kesehatan menjadi perhatian tersendiri karena di tiga desa tersebut sebagian besar belum memiliki jaminan kesehatan. Selain itu masyarakat beranggapan bahwa jaminan pemeliharaan kesehatan belum menjadi kebutuhan yang mendesak dikarenakan dalam kondisi sehat jaminan pemeliharaan kesehatan tersebut belum dibuatukan bagi masyarakat. Selain itu kurangnya sosialisasi dan prosedur yang dianggap rumit menyebabkan masyarakat enggan membuat jaminan pemeliharaan kesehatan. Peran Stakeholder tentunya sangat penting dalam mempengaruhi masyarakat untuk ikut serta dalam jaminan kesehatan. Hal ini sejalan dengan penelitian yang dilakukan oleh Nurhayani (2014), menyatakan bahwa kurangnya kesiapan Stakeholder dalam menghadapi jaminan kesehatan akan berdapak pula pada kurangnya sosialisai kepada masyarakat.

Kebiasaan merokok masyarakat di tiga desa tersebut tergolong tinggi, hal tersebut dikarenakan lingkungan sosial pada tiga desa tersebut sangat mempengaruhi kebiasaan merokok masyarakat. Lingkungan sosial yang dimaksud adalah perilaku merokok di tiga desa tersebut sudah menjadi kebiasaan yang wajar dan turun temurun. Selain itu kemudahan masyarakat dalam mendapatkan rokok juga merupakan faktor yang mempengaruhi perilaku merokok masyarakat. Hal itu selaras dengan penelitian yang dilakukan oleh Tampubolon (2011), dimana perilaku merokok sangat dipengaruhi oleh lingkungan sosial, keluarga dan teman pergaulan. Faktor yang sangat berpengaruh orang dewasa terhadap kesulitan berhenti merokok sampai saat ini adalah faktor reinforcing, diantaranya lingkungan pergaulan, kecanduan dan peran keluarga.

Pemberantasan Sarang Nyamuk (PSN) di tiga desa tersebut menjadi urutan kedua dari angka PHBS terendah. Alasannya karena keaktifan Jumantik yang mengarahkan warga dalam pemeriksaan jentik berkala serta masih rendahnya pengetahuan masyarakat mengenai pentingnya PSN dalam pencegahan penyebaran penyakit DBD. Seperti penelitian yang dilakukan oleh Suprianto (2011), terdapat hubungan antara pengetahuan, sikap, praktik keluarga tentang Pemberantasan Sarang Nyamuk (PSN) dengan kejadian Demam Berdarah Dengue di wilayah kerja Puskesmas Tlogosari Wetan Kota Semarang. 


\section{KESIMPULAN DAN SARAN}

\section{Kesimpulan}

a. Cakupan PHBS desa Gentan, Kedungsono dan Kamal masih di bawah target nasional.

b. Cakupan indikator PHBS yang nilainya terendah, yakni ketersediaan tempat sampah (37,58\%), kepemilikan JPK (49,43\%), tidak merokok (52,81\%), dan PSN (56,65\%).

c. Cakupan indikator PHBS dengan nilai tertinggi adalah tidak miras/ narkoba $(96,28 \%)$ dan ketersediaan air bersih $(94,88 \%)$.

d. Indikator Kepemilikan tempat sampah $(26,96 \%)$ di desa Gentan merupakan capaian paling rendah dari semua indikator di ketiga desa yang diteliti.

e. Indikator tidak miras/narkoba (99,1\%) di desa Kedungsono merupakan capaian paling tinggi dari semua indikator di ketiga desa yang diteliti.

\section{Saran}

a. Bagi Petugas Kesehatan

1) Mengaktifkan kader kesehatan di tiga desa tersebut.

2) Memberikan pendidikan kesehatan yang berkelanjutan dan komprehensif kepada masyarakat.

3) Melakukan pendampingan terhadap perkembangan PHBS di tiga desa tersebut.

b. Bagi Masyarakat

1) Meningkatkan kepedulian terhadap kesehatan individu, keluarga dan masyarakat dengan berperilaku hidup bersih dan sehat.

2) Mampu menjadi partner yang baik dari tenaga kesehatan dengan turut aktif dalam program yang telah disusun untuk meningkatkan derajat kesehatan masyarakat.

\section{DAFTAR PUSTAKA}

Arikunto, Suharsimi. 2006. Prosedur Penelitian Pendekatan Suatu Praktik. Jakarta: Rineka Cipta.

Ashidiqy, MR. 2009. Analisis Faktor-Faktor yang Berhubungan dengan Perilaku Masyarakat Dalam Membuang Sampah Rumah Tangga di Sungai Mranggen. Skripsi. Semarang: FIK, Ilmu Kesehatan Masyarakat.

Dinas Kesehatan Jawa Tengah. 2012. Buku Profil Kesehatan Provinsi Jawa Tengah.

DKK Sukoharjo. 2013. Profil Kesehatan Kabupaten Sukoharjo.

Kemenkes RI. 2013. Laporan Akuntabilitas Kinerja Kementrian Kesehatan Republik Indonesia.

Nurhayani., Latar, R., dan Arifin, M.A. 2014. Kesiapan Stakeholder Dalam Pelaksanaan Program Jaminan Kesehatan Nasional Di Kota Tual. Artikel Publikasi.

Puskesmas Bulu. 2013. Profil Kesehatan Puskesmas Kecamatan Bulu.

Suprianto. 2011. HubunganAntara Pengetahuan, Sikap, Praktek Keluarga tentang Pemberantasan

Sarang Nyamuk (PSN) dengan Kejadian Demam Berdarah Dengue di Wilayah Kerja Puskesmas Tlogosari Wetan Kota Semarang. Skripsi. Semarang: Undip.

Syaifuddin Azwar. 2005. Sikap Manusia Teori dan Pengukurannya. Yogyakarta: Pustaka.

Tampubolon, E . 2011. Faktor-Faktor Yang Mempengaruhi Perilaku Orang Dewasa Terhadap

Kesulitan Berhenti Merokok Di Dusun III Desa Suka Makmur Delitua Kabupaten Deli 
Serdang. Jurnal Public Health Community. Vol. 1, No.1.

Taufiq, M., Nyorong, M., dan Riskiyani, S. 2013. Gambaran Perilaku Hidup Bersih Dan Sehat (PHBS) Masyarakat Di Kelurahan Parangloe Kecamatan Tamalanrea Kota Makassar. Makasar : Universitas Hasanuddin Makassar. 